\title{
Magnetic Graphene Oxide Composites are the Solutions for Sustainable Remediation of Ecosystems
}

\author{
Lakshmi Prasanna Lingamdinne and Janardhan Reddy Koduru* \\ Department of Environmental Engineering, Kwangwoon University, South Korea \\ *Corresponding author: Janardhan Reddy Koduru, Department of Environmental Engineering, Kwangwoon University, Seoul-01897, 20 Kwangwoon \\ ro, Nowon-Gu, Republic of Korea
}

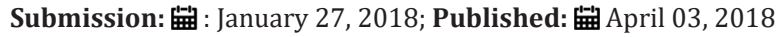

\section{Introduction}

Heavy metals are one of the primary contaminants in the environment [1]. Exposure to heavy metals, even at trace levels, is believed to be a high health risk for humans [2,3]. Heavy metals are naturally occurring throughout the earth's crust [4]. But most of the environmental contamination results from the anthropogenic activities such as mining and smelting operations, industry, and domestic and agricultural use of metals and metalcontaining compounds. Migration of these contaminants into non-contaminated areas as dust or leachates through the soil and spreading of heavy metals containing sewage sludge are a few examples of events contributing towards contamination of the ecosystems [5]. Hence, water is the one of the major routes through which heavy metals and radionuclides may enter the human body $[6,7]$. The sources of water pollution are shown in Figure 1. The conventional wastewater purification techniques including chemical coagulation, photo degradation, precipitation, flocculation, activated sludge, membrane separation and ion exchange are limited to the removal of heavy metals at trace levels [7-9]. However, adsorption is one of the best methods for the purification of water, owing to its low cost and easy handling of materials [7,10-12]. Moreover, adsorption approaches using commercial activated carbon, micro-filtration and membrane techniques are effective, but their use is limited by the complicated installation process involved coupled with the high maintenance costs of the systems $[7,13]$. Hence, these drawbacks have necessitated the search for an alternative method which is inexpensive, renewable and cost-effective for the removal of heavy metals from aqueous solutions. Many scientific groups have prepared graphene or graphene oxide (GO) based hybrid nanocomposites for various potential applications [14-17]. The study of literature survey and stability of the GO-based nanocomposites prompted us to survey on graphene oxide and reduced graphene oxide-based inverse spinel nickel ferrite nanocomposites for the removal of heavy metals and radionuclides from water with the purpose of reducing their environmental impact.



Figure 1: Schematic depict for sources of water pollution. 


\section{Graphene Oxide Based Nanocomposites for Radioactive} and Toxic Metal Remediation

Recently, the field of nanoscience has blossomed, and the importance of nanotechnology will increase as miniaturization becomes more vital in the areas of computing, sensors, biomedical, water purification and other applications. Advancements in this discipline depend largely on the ability to synthesize nanoparticles of various materials, sizes, and shapes, as well as to assemble them efficiently into complex architectures. That means, nanomaterials applications are mainly depend on their physicochemical properties which leads to develop a special structural featured nanoparticles. However, the scientists are examining materials with improved physicochemical properties that are dimensionally more suitable in the field of nanoscience and technology. In this regard, the discovery of graphene or graphene-based nanocomposites is an important addition in the area of nanoscience, playing a vital role in modern science and technology.

Graphene, a two-dimensional $\mathrm{sp}^{2}$ carbon monolayer in a unique honeycomb-like network $[18,19]$. It has attracted dramatic attention due to its numerous merits such as enormous specific surface area $(2630 \mathrm{~m} 2 / \mathrm{g})$, high thermal and electrical conductivity ( $\sim 5000 \mathrm{~W} / \mathrm{m} . \mathrm{K}$ and $6000 \mathrm{~S} / \mathrm{cm})$, large Young's modulus ( 1.0TPa) and high optical transmittance ( 97.7\%) [14,15,18-21]. Moreover, graphene oxide (GO) or graphene-based material shares merit like those of the bare. However, due to the presence of decorated hydroxyl, carboxyl, and epoxy functional groups on the basal plane and plane edge, GO is more easily dispersed than graphene, making its synthesis, processing, and usage more convenient $[22,23]$. Also, the durable hydrophilicity of GO guarantees that it is a good candidate for many applications, including drug delivery, brutal cell treatment and water purification [23-25]. To enrich the functionalities, graphene and GO are always used to host various nanomaterials due to their large surface area [22,24,25].

The incorporation of inorganic NPs to GO excellently improved its performances in different applications [26-29]. Moreover, GO is a good candidate for constructing GO-based metal oxide composite materials. For example, $\mathrm{Co}_{3} \mathrm{O}_{4}$-anchored graphene nanocomposites that serve as potential electrode materials for super capacitors exhibit an excellent specific capacitance [25]. $\mathrm{TiO}_{2}$-graphene nanocomposites display a much higher photocatalytic activity and stability for the degradation of benzene in the air [30]. Graphene$\mathrm{Fe}_{3} \mathrm{O}_{4}$ nanocomposites exhibit improved reversible capacity and cyclic stability of the lithium ion battery $[31,32]$. Recently, many researchers prepared GO-based metal oxide nanocomposites, such as $\mathrm{Fe}_{3} \mathrm{O}_{4} / \mathrm{GO}[33,34]$, Magnetic reduced GO [35,36], $\mathrm{Mn}_{3} \mathrm{O}_{4} / \mathrm{GO}[37-$ 39] and other hybrid [40-42] nanocomposites are used for the adsorption of various organic and inorganic pollutants from water. Sreeprasad et al. [41] and Maaz et al. [42] have been reported nickel ferrite-GO composite is a promising reacting media because $\mathrm{Ni}^{2+}$ in the nickel ferrites shows unique property such as high catalytic efficiency with high charge (electron) transfer capacity than iron ferrites. Therefore, it has been used for adsorption of toxic heavy metals [32]. Besides, graphene-based materials possess the ability of adsorbing organic pollutants and heavy metal ions owing to their potential adsorbent materials [42,29]. However, the limitations in separation and the following recycling process have significantly restricted their applications [29,39-43]. Nevertheless, the introduction of magnetic NPs to the graphene/GO can improve the graphene's dynamic adsorption behavior as well as overcoming the separation and recycling problem. Previous reports have proved the magnetic NPs/graphene or GO composites amazing removal response for pollutants, like chromium [44,45], copper [46,47], arsenic [33,48], cadmium [49], lead [50], cobalt and organic dye [51-53].

For the synthesis of GO-based magnetic nanocomposites, GO is the candidate used as a template to the in-situ production of magnetic NPs by interacting with the functionalized oxygencontaining groups [51,52]. A further reduction process is performed to obtain few layered graphene or reduced GO (r-GO) nanocomposites of an enhanced magnetization [52]. Recently, we reported on the synthesis of graphene oxide based inverse spinel nickel ferrite nanocomposites for the removal of heavy metals, $\mathrm{Co}(\mathrm{II}), \mathrm{Pb}(\mathrm{II}), \mathrm{Cr}(\mathrm{III}), \mathrm{As}(\mathrm{III})$ and $\mathrm{As}(\mathrm{V})$ and radionuclides, $\mathrm{U}(\mathrm{VI})$ and Th(IV) from aqueous solutions, thereby reducing potential effects on human health and environmental risks [53-58]. The reported results demonstrated that the magnetic GO-based nanocomposites, are promising, economic and could be separated by external magnetic field, and were recycled and re-used for up to five cycles without any significant loss of adsorption capacity towards heavy metals and radionuclides from aqueous environment.

\section{References}

1. Namor de AF, El Gamouz A, Frangie S, Martinez V, Valiente L, et al. (2012) Turning the volume down on heavy metals using tuned diatomite. A review of diatomite and modified diatomite for the extraction of heavy metals from water. Journal of Hazardous Materials 241-242: 14-31.

2. Tchounwou PB, Yedjou CG, Patlolla AK, Sutton DJ (2012) Heavy metal toxicity and the environment. In Molecular Clinical and Environmental Toxicology 101: 133-164.

3. Duruibe JO, Ogwuegbu MO, Egwurugwu JN (2007) Heavy metal pollution and human biotoxic effects. International Journal of Physical Sciences 2(5): 112-118.

4. Reimann C, de Caritat P (2005) Distinguishing between natural and anthropogenic sources for elements in the environment: regional geochemical surveys versus enrichment factors. Science of the Total Environment 337(1-3): 91-107.

5. Tangahu BV, Sheikh Abdullah SR, Basri H, Idris M, Anuar N, et al. (2011) A review on heavy metals ( $\mathrm{As}, \mathrm{Pb}$, and $\mathrm{Hg}$ ) uptake by plants through phytoremediation. International Journal of Chemical Engineering p. 31.

6. Förstner U, Wittmann GT (2012) Metal pollution in the aquatic environment. Springer Study Edition.

7. Abbas A, Al-Amer AM, Laoui T, Al-Marri MJ, Nasser MS, et al. (2016) Heavy metal removal from aqueous solution by advanced carbon nanotubes: critical review of adsorption applications. Separation and Purification Technology 157: 141-161.

8. Awual MR (2016) Assessing of lead (III) Capturing from contaminated wastewater using ligand doped conjugate adsorbent. Chemical Engineering Journal 289: 65-73. 
9. Shahat A, Awual MR, Khaleque MA, Alam MZ, Naushad M, et al. (2015) Large-pore diameter nano-adsorbent and its application for rapid lead (II) detection and removal from aqueous media. Chemical Engineering Journal 273: 286-295.

10. Liu C, Bai R, San Ly Q (2008) Selective removal of copper and lead ions by diethylenetriamine-functionalized adsorbent: behaviors and mechanisms. Water Research 42(6-7): 1511-1522.

11. Perić J, Trgo M, Medvidović NV (2004) Removal of zinc, copper and lead by natural zeolite a comparison of adsorption isotherms. Water research 38(7): 1893-1899.

12. Yang S, Li J, Shao D, Hu J, Wang X (2009) Adsorption of Ni (II) on oxidized multi-walled carbon nanotubes: effect of contact time, $\mathrm{pH}$, foreign ions and PAA. Journal of Hazardous Materials 166(1): 109-116.

13. Lingamdinne LP, Roh H, Choi YL, Koduru JR, Yang JK, et al. (2015) Influencing factors on sorption of TNT and RDX using rice husk biochar. Journal of Industrial and Engineering Chemistry 32: 178-186.

14. Huang X, Qi X, Boey F, Zhang H (2012) Graphene-based composites. Chemical Society Reviews 41(2): 666-686.

15. Stankovich S, Dikin DA, Dommett GH, Kohlhaas KM, Zimney EJ, et al. (2006) Graphene-based composite materials. Nature 442(7100): 282 286.

16. Scheuermann GM, Rumi L, Steurer P, Bannwarth W, Mülhaupt R (2009) Palladium nanoparticles on graphite oxide and its functionalized graphene derivatives as highly active catalysts for the Suzuki-Miyaura coupling reaction. Journal of the American Chemical Society 131(23): 8262-8270.

17. Myung S, Park J, Lee H, Kim KS, Hong S (2010) Ambipolar memory devices based on reduced graphene oxide and nanoparticles. Advanced Materials 22(18): 2045-2049.

18. Zhu Y, Murali S, Cai W, Li X, Suk JW, et al. (2010) Graphene and graphene oxide: synthesis, properties, and applications. Advanced materials 22(35): 3906-3924.

19. Mukhopadhyay P, Gupta RK (2012) Graphite, Graphene, and their polymer nanocomposites. CRC Press, Boca Raton, Florida.

20. Blake P, Brimicombe PD, Nair RR, Booth TJ, Jiang D, et al. (2008) Graphene-based liquid crystal device. Nano letters 8(6): 1704-1708.

21. Novoselov KS, Fal VI, Colombo L, Gellert PR, Schwab MG, et al. (2012) A roadmap for graphene. Nature 490(7419): 192-200.

22. Bielawski CW, Dreyer DR, Park S, Ruoff RS (2010) The chemistry of grapheme oxide. Chemical Society Reviews 39(1): 228-240.

23. Chung C, Kim YK, Shin D, Ryoo SR, Hong BH, et al. (2013) Biomedical applications of graphene and graphene oxide. Accounts of Chemical Research 46(10): 2211-2224.

24. Kyzas GZ, Deliyanni EA, Matis KA (2014) Graphene oxide and its application as an adsorbent for wastewater treatment. Journal of Chemica Technology and Biotechnology 89(2): 196-205.

25. Zhu J, Chen M, Qu H, Zhang X, Wei H, et al. (2012) Interfacial polymerized polyaniline/graphite oxide nanocomposites toward electrochemical energy storage. Polymer 53(25): 5953-5964

26. Eda G, Fanchini G, Chhowalla M (2008) Large-area ultrathin films of reduced graphene oxide as a transparent and flexible electronic material. Nature Nanotechnology 3(5): 270-274.

27. Liu Y, Yu D, Zeng C, Miao ZC, Dai L (2010) Biocompatible graphene oxide-based glucose biosensors. Langmuir 26(9): 6158-6160.

28. Ren X, Jing X, Liu L, Guo L, Zhang M, et al. (2014) Easy preparation of an MRI contrast agent with high longitudinal relaxivity based on gadolinium ions loaded graphene oxide. RSC Advances 4(96): 53987-53992.

29. Zhu J, Sadu R, Wei S, Chen DH, Haldolaarachchige N, et al. (2012) Mag- netic graphene nanoplatelet composites toward arsenic removal. ECS Journal of Solid State Science and Technology 1: M1-M5

30. Yuan J, Zhu J, Bi H, Meng X, Liang S, et al. (2013) Graphene-based 3D composite hydrogel by anchoring $\mathrm{Co}_{3} \mathrm{O}_{4}$ nanoparticles with enhanced electrochemical properties. Physical Chemistry Chemical Physics 15(31): 12940-12945.

31. Zhang Y, Tang ZR, Fu X, Xu YJ (2010) TiO -graphene nanocomposites for gas-phase photocatalytic degradation of volatile aromatic pollutant: is tio ${ }_{2}$-graphene truly different from other $\mathrm{TiO}_{2}$-carbon composite materials? ACS Nano 4(12): 7303-7314.

32. Zhou G, Wang DW, Li F, Zhang L, Li N, et al. (2010) Graphene-wrapped $\mathrm{Fe}_{3} \mathrm{O}_{4}$ anode material with improved reversible capacity and cyclic stability for lithium ion batteries. Chemistry of Materials 22(18): 53065313.

33. Yao Y, Miao S, Liu S, Ma LP, Sun H, et al. (2012) Synthesis, characterization, and adsorption properties of magnetic $\mathrm{Fe}_{3} \mathrm{O}_{4} @$ graphene nanocomposite. Chemical Engineering Journal 184: 326-332.

34. Chandra V, Park J, ChunY, LeeJ W, Hwang IC, et al. (2010) Water-dispersible magnetite-reduced graphene oxide composites for arsenic removal. ACS Nano 4(7): 3979-3986.

35. Bai S, Shen X, Zhong X, Liu Y, Zhu G, et al. (2012) One-pot solvothermal preparation of magnetic reduced graphene oxide-ferrite hybrids for organic dye removal. Carbon 50(6): 2337-2346.

36. Sun XZ, Li DX (2013) The study of catalytic oxidation of NOx using $\mathrm{Mn}_{3} \mathrm{O}_{4} / \mathrm{GO} / \mathrm{PMS}$. Advanced Materials Research 834-836: 458-461.

37. Su RJ, Zhu MC, Sun XZ, Guan J (2015) An environment-friendly method to catalytically oxidate NO in waste water by supported manganese oxide on graphite oxide. Applied Mechanics and Materials 768: 3-9.

38. Sun XZ, Li DX (2013) The comparative study of NOx oxidation using PMS catalyzed by $\mathrm{Co}_{3} \mathrm{O}_{4} / \mathrm{GO}$ and $\mathrm{Mn}_{3} \mathrm{O}_{4} / \mathrm{GO}$. Advanced Materials Research 772: 215-218.

39. Wang H, Yuan X, Wu Y, Huang H, Peng X, et al. (2013) Graphene-based materials: Fabrication, characterization and application for the decontamination of wastewater and waste gas and hydrogen storage/generation. Advanced Colloid and Interface Science 195-196: 19-40.

40. Li B, Cao H, Yin G, Lu YY (2011) $\mathrm{Cu}_{2}$ O@reduced graphene oxide composite for removal of contaminants from water and super capacitors. Journal of Materials Chemistry 21(29): 10645-10648.

41. Sreeprasad TS, Maliyekkal SM, Lisha KP, Pradeep T (2011) Reduced graphene oxide-metal/metal oxide composites: Facile synthesis and application in water purification. Journal of Hazardous Materials 186(1): 921-931.

42. Maaz K, Karim S, Mumtaz A, Hasanain SK, Liu JDuan JL (2009) Synthesis and magnetic characterization of nickel ferrite nano particles prepared by co-precipitation route. Journal of Magnetism and Magnetic Materials 321(12): 1838-1842.

43. Deng JH, Zhang XR, Zeng GM, Gong JL, Niu QY, Liang J (2013) Simultaneous removal of $\mathrm{Cd}$ (II) and ionic dyes from aqueous solution using magnetic graphene oxide nanocomposite as an adsorbent. Chemical Engineering Journal 226: 189-200.

44. Ahmet S, Mustafa T, Mustafa S (2007) Adsorption of Pb (II) and Cr (III) from aqueous solution on Celtek clay. Journal of Hazardous Materials 144(1-2): 41-46.

45. Gollavelli G, Chang CC, Ling YC (2013) Facile synthesis of smart magnetic graphene for safe drinking water: heavy metal removal and disinfection control. ACS Sustainable Chemistry 1(5): 462-472.

46. Li J, Zhang S, Chen C, Zhao G, Yang X, et al. (2012) Removal of Cu (II) and fulvic acid by graphene oxide nanosheets decorated with $\mathrm{Fe}_{3} \mathrm{O}_{4}$ nano particles. ACS Applied Materials \& Interfaces 4(9): 4991-5000. 
47. Hu X, Liu Y, Wang H, Chen A, Zeng G, et al. (2013) Removal of Cu (II) ions from aqueous solution using sulfonated magnetic graphene oxide composite. Separation and Purification Technology 108:189-195.

48. Zhu J, Sadu R, Wei S, Chen DH, Haldolaarachchige N, et al. (2012) Magnetic graphene nanoplatelet composites toward arsenic removal. ECS Journal of Solid State Science and Technology 1: M1-M5.

49. Deng JH, Zhang XR, Zeng GM, Gong JL, Niu QY, et al. (2013) Simultaneous removal of Cd (II) and ionic dyes from aqueous solution using magnetic graphene oxide nanocomposite as an adsorbent. Chemical Engineering Journal 226: 189-200.

50. Zhang W, Shi X, Zhang Y, Gu W, Li B, et al. (2013) Synthesis of water-soluble magnetic graphene nanocomposites for recyclable removal of heavy metal ions. Journal of Materials Chemistry 1(5): 1745-1753.

51. Sun H, Cao L, Lu L (2011) Magnetite/reduced graphene oxide nanocomposites: One step Solvothermal synthesis and use as a novel platform for removal of dye pollutants. Nano Research 4(6): 550-562.

52. Ai L, Zhang C, Chen Z (2011) Removal of methylene blue from aqueous solution by a solvothermal-synthesized graphene/magnetite composite. Journal of Hazardous Materials192: 1515-1524
53. Lingamdinne LP, Koduru JR, Roh H, Choi YL, Chang YY, et al. (2016) Adsorption removal of $\mathrm{Co}(\mathrm{II})$ from waste-water using graphene oxide. Hydrometallurgy 165(1): 90-96

54. Lingamdinne LP, Choi YL, Kim IS, Chang YY, Koduru JR, et al. (2016) Porous graphene oxide based inverse spinel nickel ferrite nanocomposites for the enhanced adsorption removal of arsenic. RSC Advances 6(77): 73776-73789.

55. Lingamdinne LP, Choi YL, Kim IS, Chang YY, Koduru JR, et al. (2017) Preparation and characterization of porous reduced graphene oxide based inverse spinel nickel ferrite nanocomposite for adsorption removal of radionuclides. Journal of Hazardous Materials 326: 145-156.

56. Lingamdinne LP, Kim IS, Ha JH, Chang YY, Koduru JR, et al. (2017) Enhanced adsorption removal of $\mathrm{pb}(\mathrm{ii})$ and $\mathrm{cr}(\mathrm{iii})$ by using nickel ferrite-reduced graphene oxide nanocomposite. Metals 7(6): 225.

57. Lingamdinne LP, Koduru JR, Chang YY, Karri RR (2018) Process optimization and adsorption modeling of $\mathrm{Pb}$ (II) on nickel ferrite-reduced graphene oxide nano-composite. Journal of Molecular Liquids 250: 202-211.

58. Lingamdinne LP, Koduru JR, Choi YL, Chang YY, Yang JK (2016) Studies on removal of $\mathrm{Pb}$ (II) and $\mathrm{Cr}$ (III) using graphene oxide basedinverse spinel nickel ferrite nano-composite as sorbent. Hydrometallurgy 165(1): 64-72.
Creative Commons Attribution 4.0 International License

For possible submissions Click Here

\section{Submit Article}

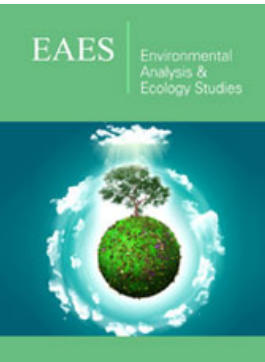

Environmental Analysis \& Ecology Studies

\section{Benefits of Publishing with us}

- High-level peer review and editorial services

- Freely accessible online immediately upon publication

- Authors retain the copyright to their work

- Licensing it under a Creative Commons license

- Visibility through different online platforms 